\title{
Investigation of the single layer model of GPS ionospheric data processing using IRI-90 and the attached diffusive equilibrium model of plasmaspheric electron density
}

\author{
László Bányai \\ Geodetic and Geophysical Research Institute, Hungarian Academy of Sciences, Sopron, Hungary
}

\begin{abstract}
The single layer model of GPS ionospheric data processing is compared with the International Reference Ionosphere - 1990 and the attached Diffusive Equilibrium model of Plasmasphere (IRI-90+DEP) which proved to be a good supplement to GPS data processing. These models can be used to estimate the single layer height and to improve the mapping function in day-time. The code delays estimated from IRI-90+DEP models are compared with GPS measurements carried out by TurboRogue receiver. These models can be used to estimate the preliminary receiver biases especially in the case of cross-correlation tracking mode. The practical drawback of the IRI-90 model is the sharp discontinuity of the ion components during sunset and sunrise at an elevation of $1000 \mathrm{~km}$, because it also causes a sharp discontinuity in the TEC values computed from the DEP model. The GPS data may be a good source to improve the topside region of the IRI model estimating smooth TEC transition before and after sunrise in the plasmasphere.
\end{abstract}

Key words GPS measurements - single layer model - total electron content - ionosphere plasmasphere

\section{Introduction}

One of the most crucial points of ionospheric investigation by means of the GPS technique is the separation of the measured Total Electron Content (TEC) and the code synchronization biases of satellites and receivers (Wanninger et al., 1994).

Mailing address: Dr. László Bányai, Geodetic and Geophysical Research Institute, Hungarian Academy of Sciences, P.O. Box 5, H-9401 Sopron, Hungary; e-mail: banyai@ggki.hu
Pure application of the ionospheric models is not recommended because of model uncertainties; moreover, the pure application of GPS data is based on polynomial approximation of vertical TEC data and the reported satellite biases show wide variety (Klobuchar et al., 1994).

This paper investigates the single layer model of GPS data processing using the data estimated by International Reference Ionosphere - 1990 and the attached Diffusive Equilibrium model of Plasmasphere (IRI-90+ DEP).

Using this model the daily, seasonal and solar cyclic applicability of the single layer model can be investigated without real GPS observations. However - to keep the manu- 
script in a reasonable size - only representative investigations are presented, where real data are available from the special observations that were used to compare the P-Code (PCD) and Cross-Correlation (XCR) tracking modes of TurboRogue GPS receiver (Bányai and EperPápai, 1996).

The comparison of the models supported by experimental GPS data would be very important for the whole solar cycle ( $c a .11$ years), because in the present solar minimum period the ionospheric effects seem to be a minor problem for high precision GPS applications. These investigations can be carried out after the end of the present cycle.

\section{IRI-90 and Diffusive Equilibrium model of the Plasmasphere}

One of the best experimental models, the International Reference Ionosphere updated in 1990 (IRI-90) is widely used by aeronomists to describe the different features of the ionosphere. The structure of the model is summarized in fig. 1. The input parameters are the geographic (or geomagnetic) latitude and longitude, the height above the surface, the month, the local (or universal) time of the investigated point as well as the sunspot number.

Unfortunately the topside region is modelled only up to a height of $1000 \mathrm{~km}$, therefore to estimate the TEC values of GPS observations an additional plasmaspheric electron density $(N)$ model is needed (Klobuchar and Leitinger, 1993). Lacking a more suitable model, the diffusive equilibrium model (Bauer, 1973) was chosen

$$
N=N_{0}\left[\frac{\sum_{j} N_{j 0} \exp \left(-\frac{z}{H_{j}}\right)}{\sum N_{j 0}}\right]^{1+e}
$$

where

$$
H_{j}=k T_{i} / m_{j} g
$$

$k$ is the Boltzman constant, $m$ the molecular

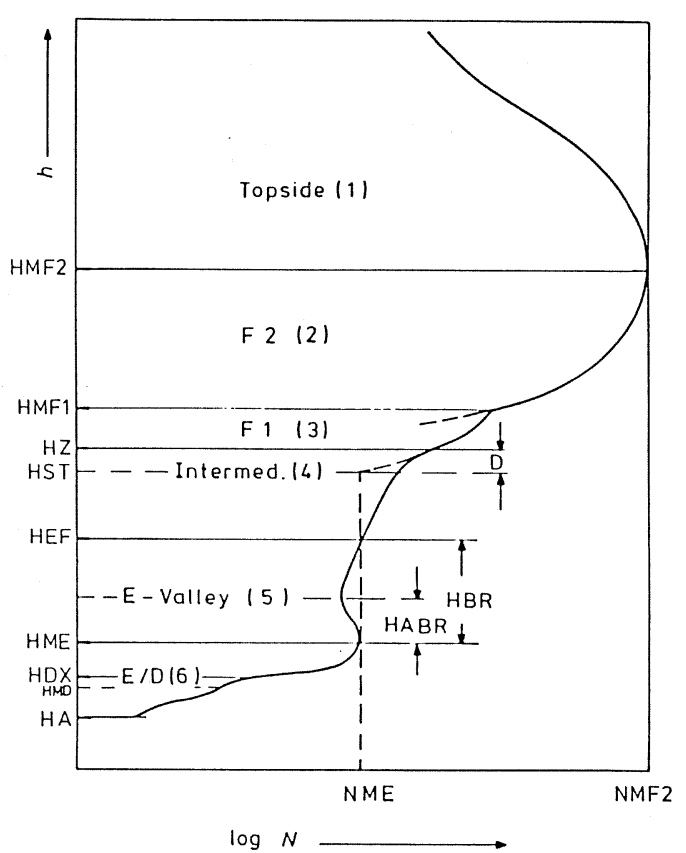

Fig. 1. The structure of the IRI model (Lincoln and Conkright, 1981).

weight, $g$ the gravity, $T_{j}$ the ion temperature, $e$ the ratio of the electron and ion temperature, $N_{0}$ the electron density at $1000 \mathrm{~km}, z$ the height above $1000 \mathrm{~km}$ and $j=3\left(\mathrm{O}^{+}, \mathrm{H}^{+}, \mathrm{He}^{+}\right.$components). All the necessary parameters can be estimated by the IRI-90 model.

One example of the model computations can be found in table I. Except for the different $E / D$ region heights, the IRI-90 model predicts a smooth TEC transition before and after sunrise. The discontinuity in the plasmaspheric model is caused by sharp differences in the ion components.

\section{Single layer model and GPS observables}

According to the single layer model of GPS investigation the ionosphere is approximated as a spherical shell around the Earth at the properly chosen height $\left(h_{m}\right)$ above the surface 
Table I. Vertical Total Electron Content values (VTEC-el $/ \mathrm{m}^{3}$ ) and the corresponding delays on the code measurements and on their ionospheric combinations (L1, L2, IC $=\mathrm{L} 2-\mathrm{L} 1-m ; \mathrm{M}=$ median; $\mathrm{E}=$ expected value). The heights of the regions are in kilometers. Lat. $47.7^{\circ}$, Long. 16.6 ${ }^{\circ}$, 23th May, 1994. Sunspot number: 19.

\begin{tabular}{|c|c|c|c|c|c|c|c|}
\hline \multirow{8}{*}{$\begin{array}{l}E / D \text { region } \\
E \text { valley } \\
\text { Intermed. } \\
F 1 \text { region } \\
F 2 \text { region } \\
\text { Topside } \\
\text { Plasmasp. }\end{array}$} & \multirow{8}{*}{$\begin{array}{c}\text { VTEC } \\
.198503 \mathrm{E}+15 \\
.578462 \mathrm{E}+15 \\
.550266 \mathrm{E}+16 \\
.000000 \mathrm{E}+00 \\
.747333 \mathrm{E}+16 \\
.332362 \mathrm{E}+17 \\
.897251 \mathrm{E}+16\end{array}$} & \multicolumn{2}{|c|}{ Height } & \multirow{2}{*}{$\begin{array}{l}\text { IC } \\
.00\end{array}$} & \multirow{2}{*}{$\begin{array}{l}\text { L1 } \\
.00\end{array}$} & \multirow{2}{*}{$\frac{\mathrm{L} 2}{.01}$} & \multirow{2}{*}{$\begin{array}{c}\text { Local time } \\
4: 33: 00\end{array}$} \\
\hline & & 80. & 105. & & & & \\
\hline & & 105. & 146. & .01 & .01 & .02 & \multirow{2}{*}{ before sunrise } \\
\hline & & 146. & 243. & .06 & .09 & .15 & \\
\hline & & 243. & 243. & .00 & .00 & .00 & \multirow{2}{*}{$\begin{array}{l}\text { plasmaspheric } \\
\text { components }\end{array}$} \\
\hline & & 243. & 291. & .08 & .12 & .20 & \\
\hline & & 291. & 1000. & .35 & .54 & .89 & $\begin{array}{lll}\mathrm{O}^{+} & \mathrm{H}^{+} & \mathrm{He}^{+}\end{array}$ \\
\hline & & 1000 & 20200 & .09 & .15 & .24 & \multirow[t]{4}{*}{$7 \% \quad 83 \% \quad 9 \%$} \\
\hline Total & $.559616 \mathrm{E}+17$ & 80. & 20200. & .59 & .91 & 1.50 & \\
\hline $\mathrm{M}$ - range & $.279906 \mathrm{E}+17$ & 80. & 383. & .29 & .45 & .75 & \\
\hline $\mathrm{E}$ - range & $.422790 \mathrm{E}+17$ & 80. & 650. & .44 & .69 & 1.13 & \\
\hline$E / D$ region & $.200329 E+15$ & 80. & 105. & .00 & .00 & .01 & \multirow{3}{*}{$\begin{array}{l}4: 33: 30 \\
\text { before sunrise }\end{array}$} \\
\hline$E$ valley & $.584026 \mathrm{E}+15$ & 105. & 146. & .01 & .01 & .02 & \\
\hline Intermed. & $.553258 \mathrm{E}+16$ & 146. & 243. & .06 & .09 & .15 & \\
\hline$F 1$ region & $.000000 \mathrm{E}+00$ & 243. & 243. & .00 & .00 & .00 & \multirow{2}{*}{$\begin{array}{l}\text { plasmaspheric } \\
\text { components }\end{array}$} \\
\hline$F 2$ region & $.747861 \mathrm{E}+16$ & 243. & 291. & .08 & .12 & .20 & \\
\hline Topside & $.333009 E+17$ & 291. & 1000. & .35 & .54 & .89 & \multirow{5}{*}{$\begin{array}{ccc}\mathrm{O}^{+} & \mathrm{H}^{+} & \mathrm{He}^{+} \\
7 \% & 83 \% & 9 \%\end{array}$} \\
\hline Plasmasp. & $.900134 \mathrm{E}+16$ & 1000. & 20200 & .09 & .15 & .24 & \\
\hline Total & $.560978 \mathrm{E}+17$ & 80. & 20200. & .59 & .91 & 1.50 & \\
\hline $\mathrm{M}$ - range & $.280587 \mathrm{E}+17$ & 80. & 383. & .29 & .46 & .75 & \\
\hline E - range & $.423899 \mathrm{E}+17$ & 80. & 651. & .45 & .69 & 1.13 & \\
\hline$E / D$ region & $.203231 E+15$ & 65. & 105. & .00 & .00 & .01 & \multirow{2}{*}{$\begin{array}{c}\text { 4:34:00 } \\
\text { after sunrise }\end{array}$} \\
\hline$E$ valley & $.597664 \mathrm{E}+15$ & 105. & 146. & .01 & .01 & .02 & \\
\hline Intermed. & $.556255 \mathrm{E}+16$ & 146. & 243. & .06 & .09 & .15 & \\
\hline$F 1$ region & $.000000 \mathrm{E}+00$ & 243. & 243. & .00 & .00 & .00 & \multirow{2}{*}{$\begin{array}{l}\text { plasmaspheric } \\
\text { components }\end{array}$} \\
\hline$F 2$ region & $.748398 E+16$ & 243. & 291. & .08 & .12 & .20 & \\
\hline Topside & $.333661 \mathrm{E}+17$ & 291. & 1000. & .35 & .54 & .89 & \multirow{5}{*}{$\begin{array}{ccc}\mathrm{O}^{+} & \mathrm{H}^{+} & \mathrm{He}^{+} \\
49 \% & 46 \% & 5 \%\end{array}$} \\
\hline Plasmasp. & $.345139 \mathrm{E}+16$ & 1000. & 20200. & .04 & .06 & .09 & \\
\hline Total & $.506650 \mathrm{E}+17$ & 65. & 20200. & .53 & .82 & 1.35 & \\
\hline $\mathrm{M}$ - range & $.253429 \mathrm{E}+17$ & 65. & 361. & .27 & .41 & .68 & \\
\hline $\mathrm{E}$ - range & $.372914 \mathrm{E}+17$ & 65 & 490. & .39 & .61 & 1.00 & \\
\hline$E / D$ region & $.205086 \mathrm{E}+15$ & 65. & 105. & .00 & .00 & .01 & \multirow{2}{*}{$\begin{array}{l}4: 34: 30 \\
\text { after sunrise }\end{array}$} \\
\hline$E$ valley & $.603264 \mathrm{E}+15$ & 105. & 146. & .01 & .01 & .02 & \\
\hline Intermed. & $.559261 \mathrm{E}+16$ & 146. & 243. & .06 & .09 & .15 & \multirow{3}{*}{$\begin{array}{l}\text { plasmaspheric } \\
\text { components }\end{array}$} \\
\hline$F 1$ region & $.000000 \mathrm{E}+00$ & 243. & 243. & .00 & .00 & .00 & \\
\hline$F 2$ region & $.748946 \mathrm{E}+16$ & 243. & 290. & .08 & .12 & .20 & \\
\hline Topside & $.334318 \mathrm{E}+17$ & 290. & 1000 & .35 & .54 & .89 & $\mathrm{O}^{+} \quad \mathrm{H}^{+} \quad \mathrm{He}^{+}$ \\
\hline Plasmasp. & $.346342 E+16$ & 1000 & 20200 & .04 & .06 & .09 & $49 \% \quad 46 \% \quad 5 \%$ \\
\hline Total & $.507856 \mathrm{E}+17$ & 65. & 20200. & .53 & .82 & 1.36 & \\
\hline $\mathrm{M}$ - range & $.254032 \mathrm{E}+17$ & 65. & 361. & .27 & .41 & .68 & \\
\hline $\mathrm{E}$ - range & $.373933 \mathrm{E}+17$ & 65. & 490. & .39 & .61 & 1.00 & \\
\hline
\end{tabular}




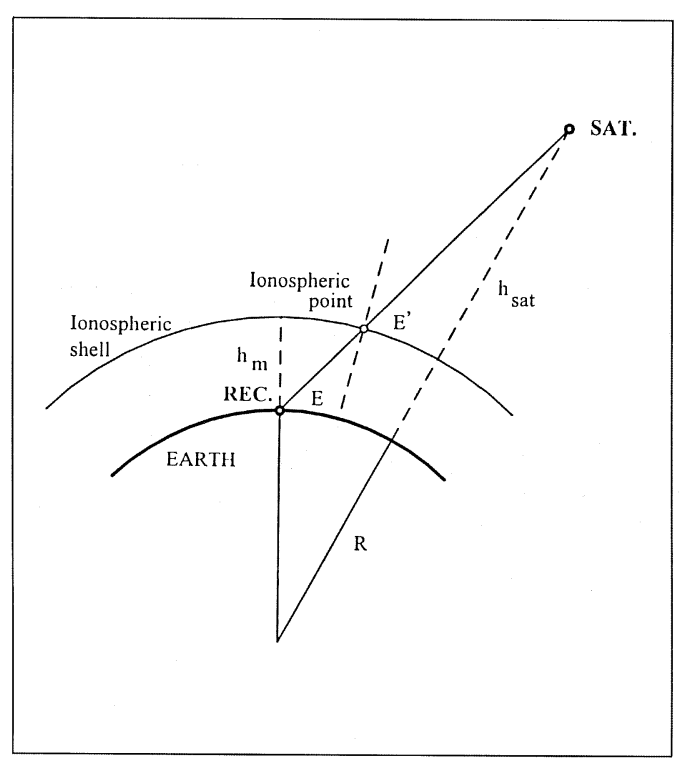

Fig. 2. The geometry of the single layer model.

(fig. 2). The intersection of this shell and the line of sight between the satellite and the receiver at given local time is defined as the ionospheric point. The elevation angle of the satellite $\left(E^{\prime}\right)$ - with respect to the ionospheric point - is used to map the measured slant TEC value to the vertical $\left(I_{v}\right)$. Because this geometric model is valid only in the case of a single layer model, the $h_{m}$ height is a basic constant. In the literature different values are proposed and usually the $400 \mathrm{~km}$ value is preferred. The IRI-90 + DEP models can be used to estimate this height. If we assume that the height is a random variable and the electron density function is proportional to the density fuction in the interval $0-h_{\text {sat }}$, where $h_{\text {sat }}$ is the satellite elevation over the surface, both the median and the expected values can be computed to estimate the most probable height. (The latter is equivalent to the weighted mean, where the weight is the electron density.) Another candidate would be the height of maximum density HMF2 (fig. 1). Table I also lists these heights.

The geometry-free linear combinations of code and phase measurements are suitable for ionospheric investigations

$$
\begin{gathered}
R_{2}-R_{1}=c\left(d t_{R}^{r}+d t_{R}^{s}\right)+ \\
+\frac{1}{\sin E^{\prime}} \frac{A}{2} \frac{f_{1}^{2}-f_{2}^{2}}{f_{1}^{2} f_{2}^{2}} I_{v}+\epsilon_{R} \\
\lambda_{2} \phi_{2}-\lambda_{1} \phi_{1}=\left(\lambda_{2} N_{2}-\lambda_{1} N_{1}\right)+c\left(d t_{\phi}^{r}+d t_{\phi}^{s}\right)- \\
-\frac{1}{\sin E^{\prime}} \frac{A}{2} \frac{f_{1}^{2}-f_{2}^{2}}{f_{1}^{2} f_{2}^{2}} I_{v}+\epsilon_{\phi}
\end{gathered}
$$

where

$R$ = pseudorange or code observable $(m)$;

$\phi \quad=$ phase observable (cycle);

$d t_{R}^{r}=$ code synchronization bias of the receiver;

$d t_{R}^{s}=$ code synchronization bias of the satellite;

$d t_{\phi}^{r}=$ phase synchronization bias of the receiver;

$d t_{\phi}^{s}=$ phase synchronization bias of the satellite;

$N=$ phase ambiguity (initial phase unknown);

$f=$ frequency $(1 / \mathrm{s})$;

$c=$ speed of light $(\mathrm{m} / \mathrm{s})$;

$\lambda=$ wavelength $(\mathrm{m})$;

$A=$ constant $\left(80.6 \mathrm{~m}^{3} \mathrm{~s}^{-2}\right)$;

$\epsilon=$ random observation errors and not modeled errors: multipath, phase center variation and higher order ionospheric effects.

The indices 1 and 2 means the L1 and L2 carriers, respectively.

The geometry- and ionosphere-free linear combinations contain only biases and observation errors

$$
\begin{gathered}
R_{2}-R_{1}+\lambda_{2} \phi_{2}-\lambda_{1} \phi_{1}=c\left(d t_{R}^{r}+d t_{R}^{s}\right)+ \\
+\left(\lambda_{2} N_{2}-\lambda_{1} N_{1}\right)+c\left(d t_{\phi}^{r}+d t_{\phi}^{s}\right)+\epsilon= \\
=A 0+A 1^{*}\left(t-t_{m}\right)+\epsilon .
\end{gathered}
$$

Theoretically this combination should be a 
constant value, but significant linear trend was experienced even in the case of P-code measurements (Bányai and Eper-Pápai, 1996). To solve this problem the polynomial fit is proposed where $t_{m}$ is the mean observation time (UT), $A 0$ contains the mean biases at $t_{m}$ and $A 1$ describes the linear trend. This model leads to the optimum ionospheric combination

$$
\begin{gathered}
\lambda_{2} \phi_{2}-\lambda_{1} \phi_{1}-A 0=-\frac{1}{\sin E^{\prime}} \frac{A}{2} \frac{f_{1}^{2}-f_{2}^{2}}{f_{1}^{2} f_{2}^{2}} I_{v}- \\
-c\left(d t_{R}^{r}+d t_{R}^{s}\right)+\epsilon_{i}
\end{gathered}
$$

which is practically the shift of (3.2), where the phase ambiguities (and biases) are replaced by the more meaningful mean code synchronization biases.

One example of these combinations can be found in figs. 3a-c, where the oscillating and the smooth curves denote the code and phase measurements from cross-correlation measure- ments respectively. In fig. $3 a$ the combinations (3.3) - with negative sign - and (3.1) show the asymmetry of the code and phase measurements; fig. $3 b$ shows the linear trend of the geometry- and ionosphere-free linear combinations; in fig. $3 \mathrm{c}$ this linear trend is removed from the code combination.

Typical examples of the standard deviations of linear fitting are given in table II for the different tracking modes of the TurboRogue GPS receiver. In the case of low elevation passes and noiser observation sites significantly worse fitting may be experienced (Bányai and Gianniou, 1997).

For the separation of code biases and ionospheric delay a proper modelling of $I_{v}$ is needed. In practice, different polynomial approximation of the $I_{v}=I_{v}(\phi, t)$ functions are used (Lanyi and Roth, 1988; Wanninger et al., 1994; Georgiadiou, 1994) where $\phi$ is the geographic latitude and $t$ is the local time of the ionospheric point.

Substituting $I_{v}$ polynomials into (3.3) the sum of the code synchronization biases and

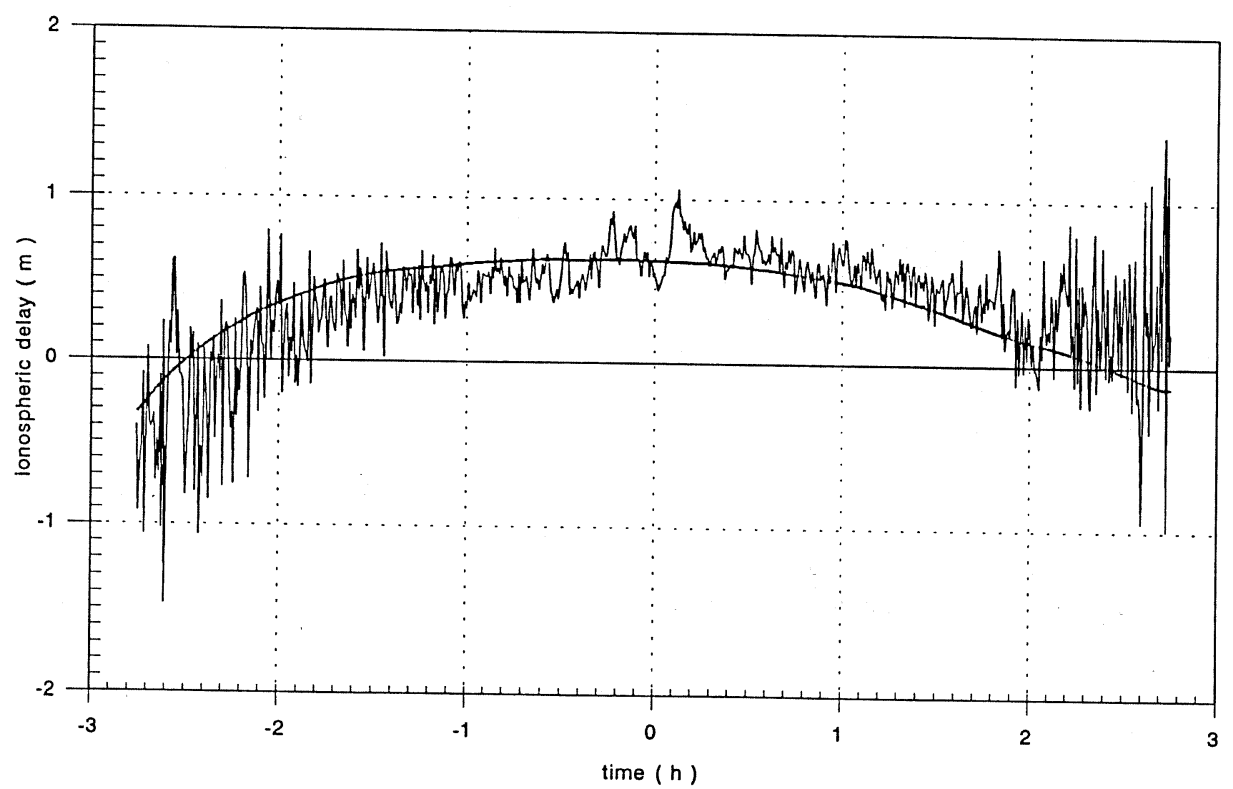

Fig. 3a. Optimum ionospheric combination (smooth line) and geometry-free code combination $\left(R_{1}-R_{2}\right)$ as functions of time relative to the mean epoch (10.10.1994, sat \# 12, XCR measurements). 


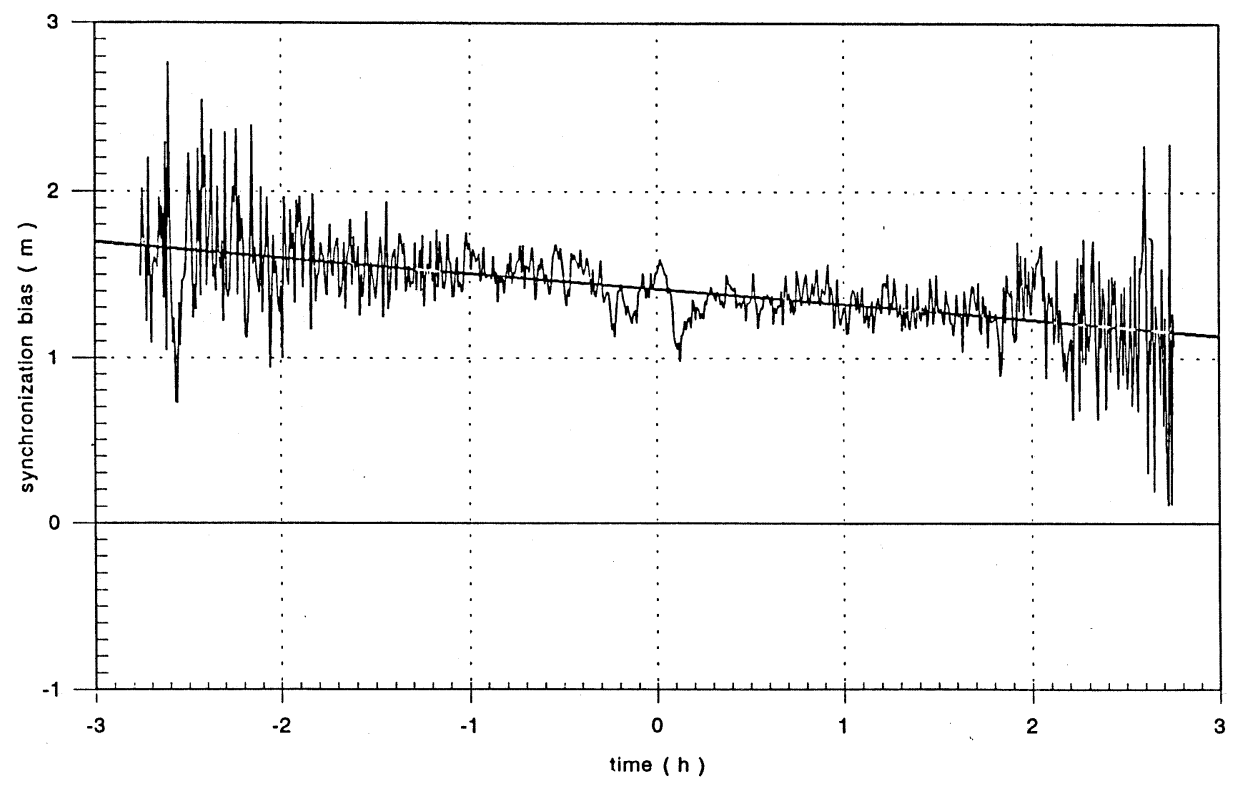

Fig. 3b. Geometry- and ionosphere-free combination together with the linear trend as functions of time relative to the mean epoch (10.10.1994, sat \# 12, XCR measurements).

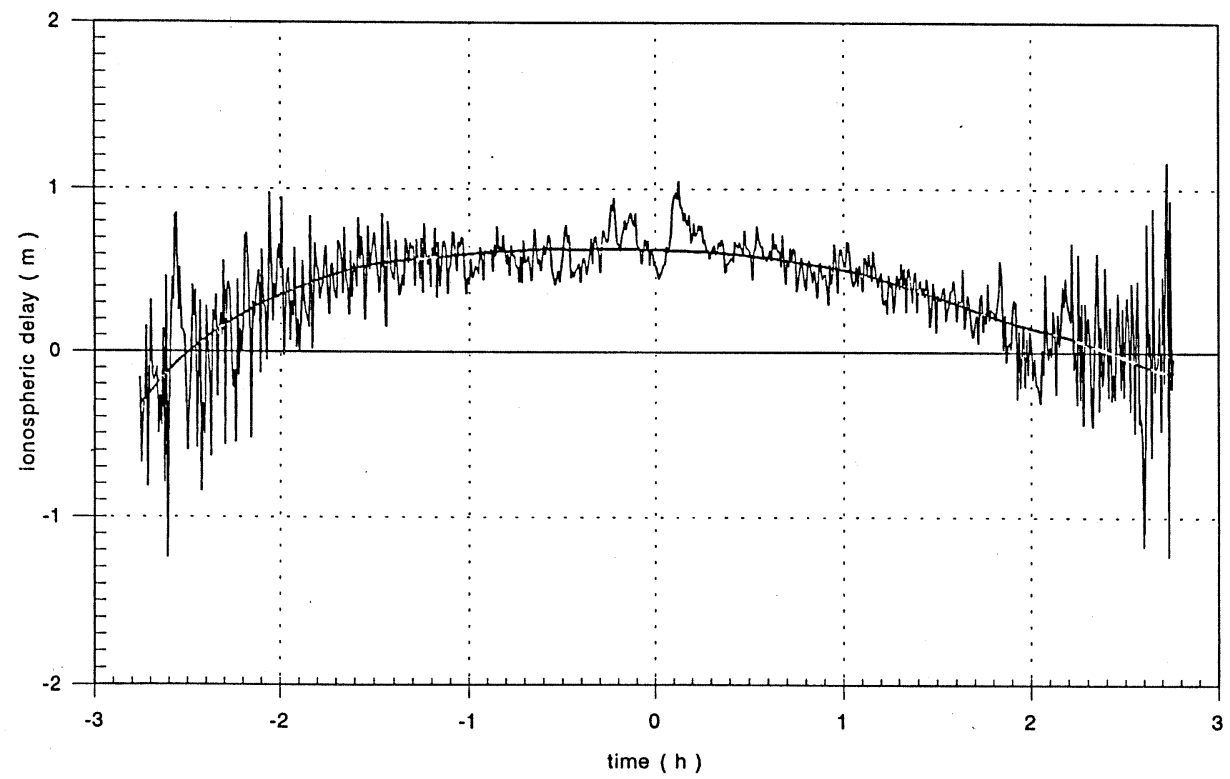

Fig. 3c. Optimum ionospheric combination (smooth line) and geometry-free code combination $\left(R_{1}-R_{2}\right)$ as functions of time relative to the mean epoch after the linear trend is removed $(10.10 .1994$, sat \# 12, XCR measurements). 
Table II. Standard deviations of the linear fit of the geometry- and ionosphere-free linear combinations $(\sigma-m)$, sat \# 12 .

\begin{tabular}{ccc}
\hline \hline Date & PCD & XCR \\
\hline 23.05 .94 & 0.0513 & 0.1717 \\
10.10 .94 & 0.0613 & 0.1540 \\
16.10 .94 & 0.0626 & 0.1647 \\
\hline
\end{tabular}

the coefficients of the polynomials can be determined by least-squares adjustment because the derivatives of the polynomials vary with $1 / \sin E^{\prime}$.

The code biases and the zero order coefficient can be separated effectively if there is a large change in the $E^{\prime}$ value; consequently the observation of a high maximum elevation and full satellite passes are needed. The observations are deleted below a reasonably chosen elevation angle e.g., 15-20 degrees.
The excepted accuracy of repeated estimation of code biases can be concluded from table II. In the case of PCD measurements 5-10 $\mathrm{cm}$, while in the case of XCR measurements $15-20 \mathrm{~cm}$ standard deviation are equivalent to 0.3 and $0.6 \mathrm{~ns}$ respectivelly.

\section{Comparison of the different models}

During the investigations the observations under a 20 degree elevation angle - with respect to the ellipsoidal normal at the observation site - are deleted and the $A 0, A 1, t_{m}$ parameters are determined. The different single layer heights $\left(h_{m}\right)$ and the corresponding ionospheric points referring to $t_{m}$ are estimated by successive approximation. The actual $h_{m}$ is held as a constant value during the processing of the satellite pass (see fig. 2).

In the following step the parameters of the ionospheric points and the corresponding verti-

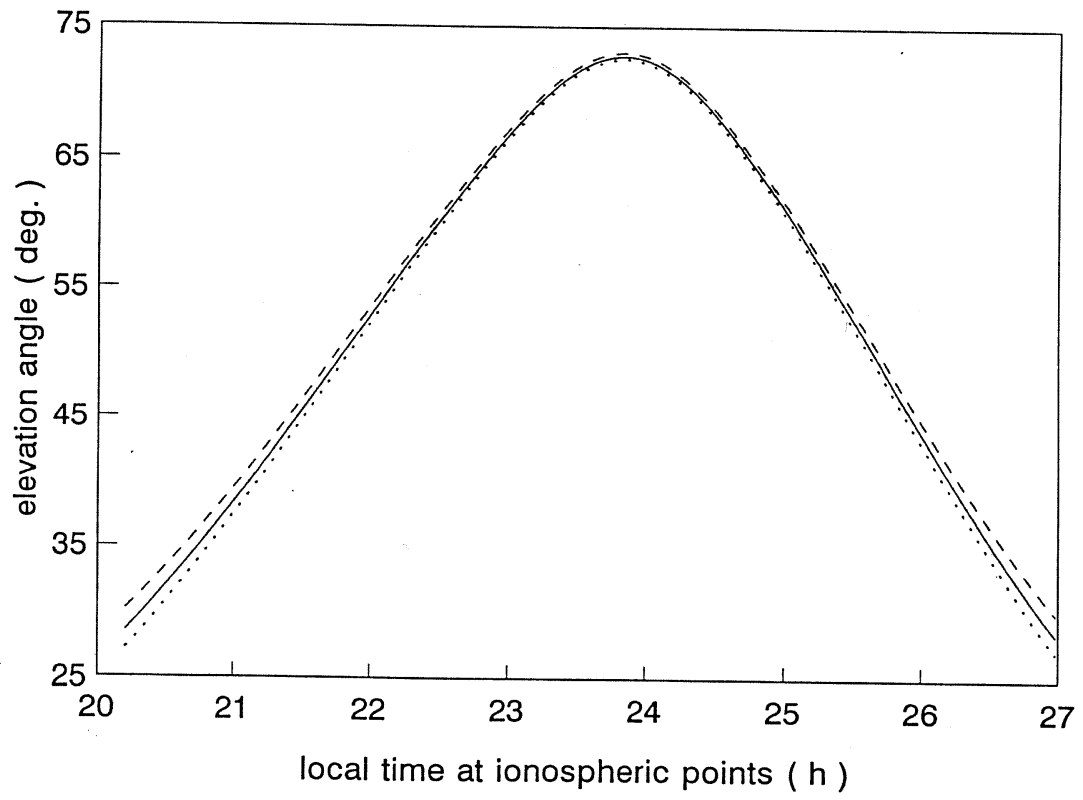

Fig. 4a. Elevation angles for different single layer heights (dashed line = expected height $538.7 \mathrm{~km}$; solid line $=$ median height $430.5 \mathrm{~km}$; dotted line $=$ HMF2 height $345.0 \mathrm{~km} ; 10.10 .1994$, sat \# 12 , sunspot
number 49). 


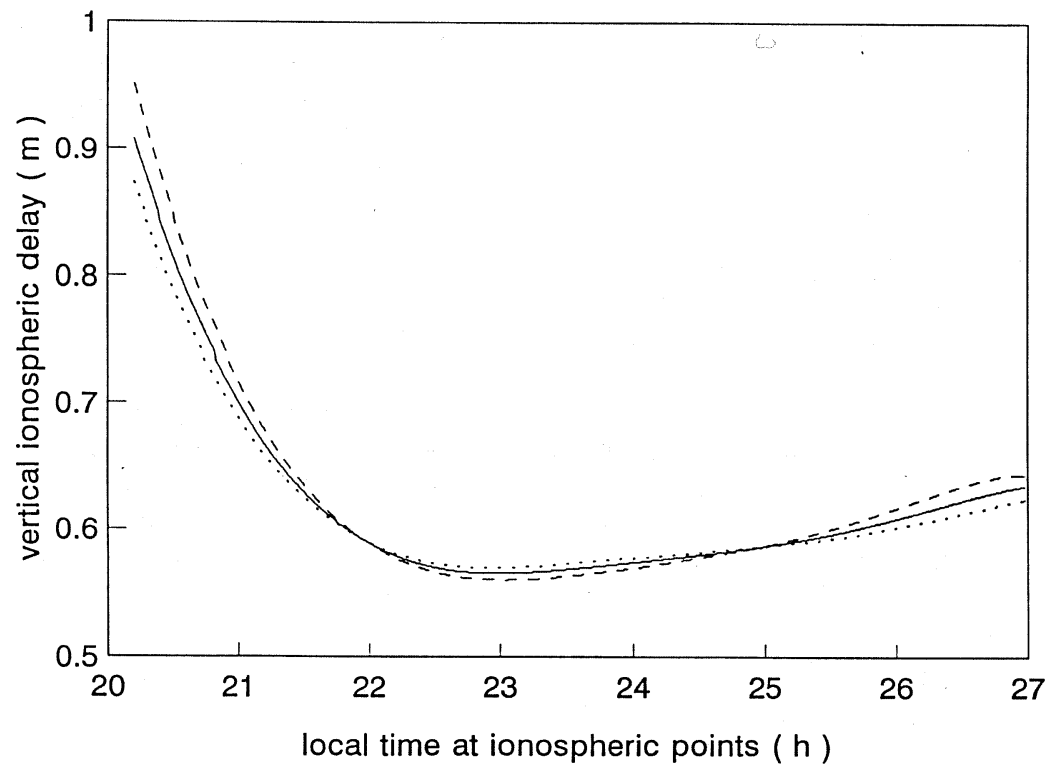

Fig. 4b. Vertical delays $\left(I_{v}\right)$ for different single layer heights (dashed line = expected height $538.7 \mathrm{~km}$; solid line = median height $430.5 \mathrm{~km}$; dotted line $=\mathrm{HMF} 2$ height $345.0 \mathrm{~km} ; 10.10 .1994$, sat \# 12, sunspot number 49).

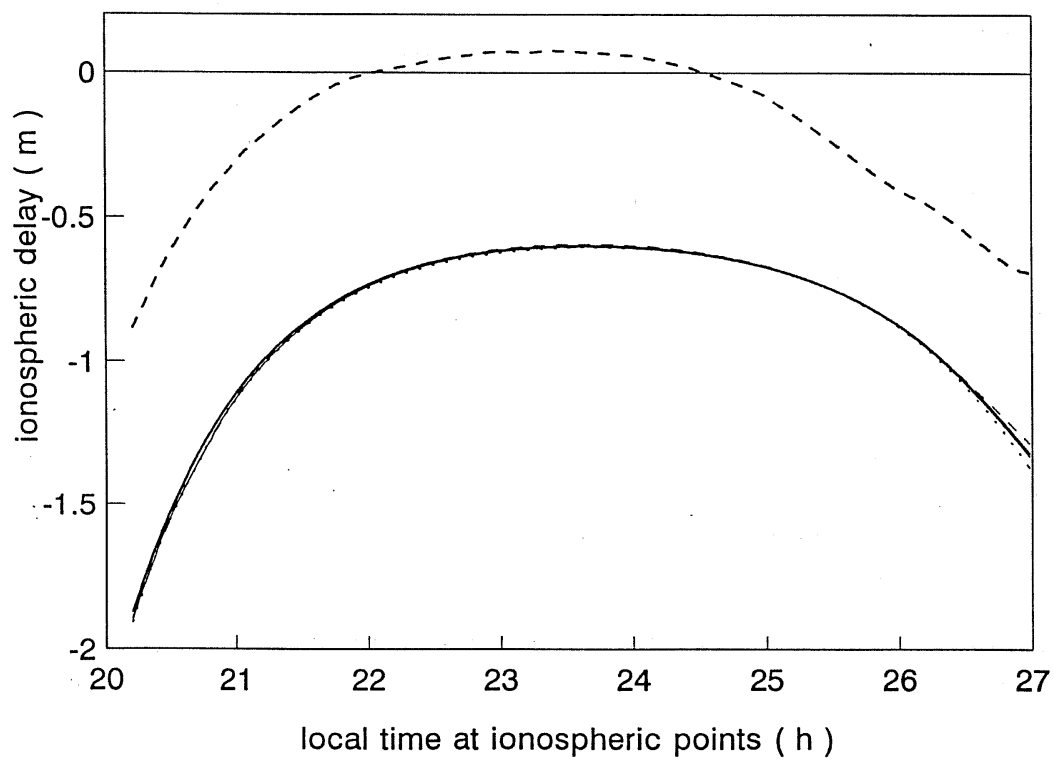

Fig. 4c. Measured, directly integrated and mapped slant delays for different single layer heights (thick dashed line = GPS PCD combinations; thick solid line = direct slant integral; dashed line $=$ expected height $538.7 \mathrm{~km}$; solid line = median height $430.5 \mathrm{~km}$; dotted line = HMF2 height $345.0 \mathrm{~km} ; 10.10 .1994$, sat \# 12, sunspot number 49). 
cal and mapped slant TEC values are determined using the IRI-90+DEP models. For the control of computations and the single layer model the direct slant TEC values are determined too. In both cases the Romberg integration is used which is quite powerful for sufficiently smooth integrands (Press et al., 1986).

The results of the investigations are summarized in figs. 4a-c and 5a-c. In figs. 4a, 5a the elevation angles and in figs. $4 \mathrm{~b}, 5 \mathrm{~b}$ vertical ionospheric delays are plotted with respect to the ionospheric points for the three different single layer heights. In figs. $4 c, 5 c$ the vertical delays are mapped by the elevation angles and are compared with the direct slant integral and measured PCD optimum ionospheric combinations. All the data are plotted as a function of local time at the ionospheric points.

In the case of night-time observations (fig. 4a-c) the differences of elevation angles and vertical delays of the different single layer heights disappear after the projection and are practically the same as the direct slant integrals. Similar conclusions can be drawn from the day-time observations (fig. 5a-c) except for the period around the sunrise. The small jump of the vertical delays are caused by the DEP model and indicates the time of sunrise. The «stairs» of the direct slant integrals are also caused by the DEP model and the jump in the HA height of the IRI-90 model. In this period the median single layer height seems to be preferable. The increasing deviation of the mapped and the direct slant integrals under 50 degree elevation is the consequence of the daytime observation, where the gradients caused by the full lower regions of the ionosphere limit the elevation region acceptable by the single layer model. These deviations can be used to improve a mapping function at daytime.

The nearly parallel lines of the model data and the measurements prove the usefulness of the single layer model and indicate the exis-

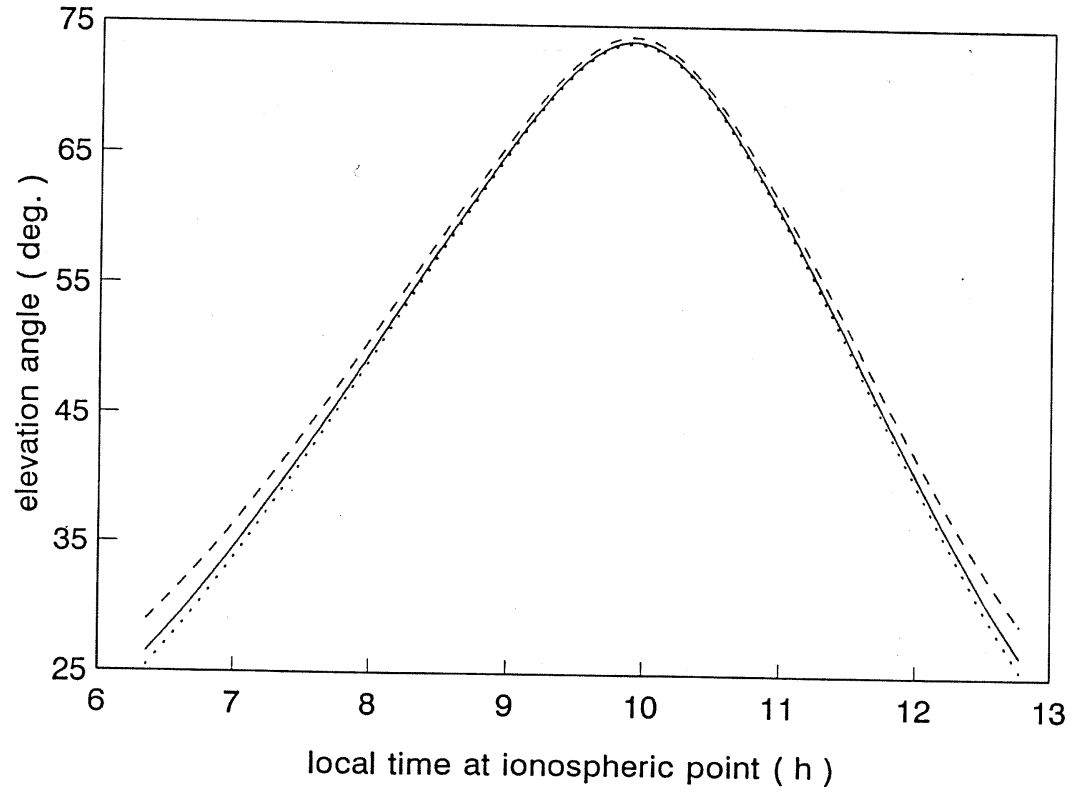

Fig. 5a. Elevation angles for different single layer heights (dashed line = expected height $461.3 \mathrm{~km}$; solid line = median height $308.3 \mathrm{~km}$; dotted line $=$ HMF2 height $247.0 \mathrm{~km} ; 23.05 .1994$, sat \# 12, sunspot number 19). 


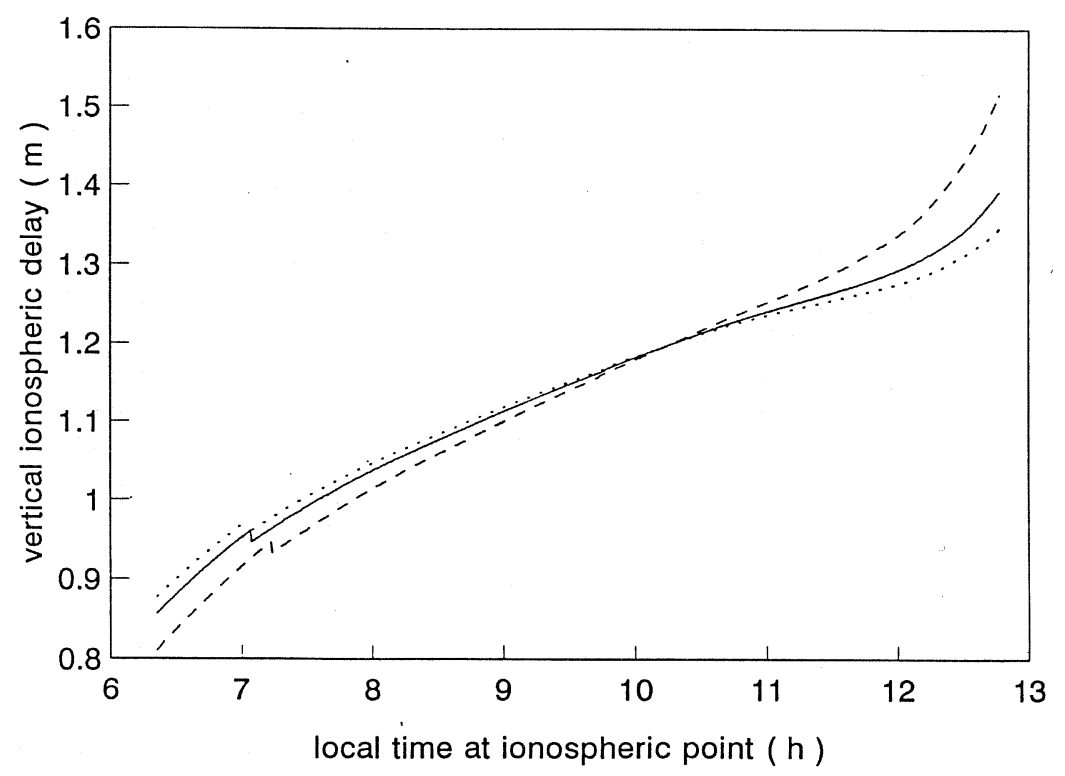

Fig. 5b. Vertical delays $\left(I_{v}\right)$ for different single layer heights (dashed line = expected height $463.1 \mathrm{~km}$; solid line $=$ median height $308.3 \mathrm{~km}$; dotted line $=H M F 2$ height $247.0 \mathrm{~km} ; 23.05 .1994$, sat \# 12, sunspot number 19).

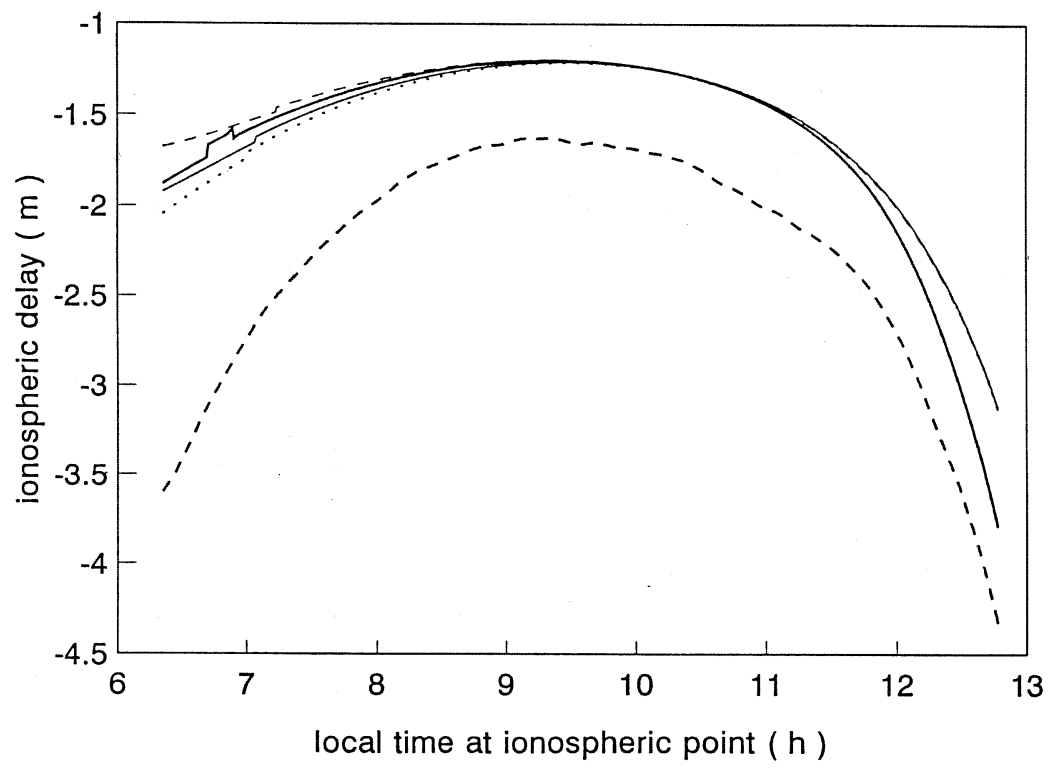

Fig. 5c. Measured, directly integrated and mapped slant delays for different single layer heights (thick dashed line $=$ GPS PCD combinations; thick solid line $=$ direct slant integral; dashed line $=$ expected height $463.1 \mathrm{~km}$; solid line = median height $308.3 \mathrm{~km}$; dotted line = HMF2 height $247.0 \mathrm{~km} ; 23.05 .1994$, sat \# 12, sunspot number 19). 
tence of the code synchronization biases. The differences are larger at lower elevations and near to sunrise (fig. 5a-c).

According to the definition of (3.3) all the data should have a negative sign, however in fig. $4 \mathrm{c}$ positive PCD data regions can be found. This is the consequence of the code synchronization biases and the possible low electron density at night-time. These discrepancies can be explained from a statistical point of view by the $3 \sigma$ confidence interval (see table II) which shows the limitation of the absolute TEC determination using the GPS technique. If we assume that the IRI-90 + DEP models can predict the delays with similar accuracy, then the preliminary biases should be determined from the differences of the model and measured data, especially in the case of XCR observations.

\section{Conclusions}

The IRI-90 and the Diffusive Equilibrium model of Plasmaspheric electron density proved to be a good supplement to the single layer model of GPS ionospheric data processing. These models can be used to estimate the single layer height and to improve a mapping function or indicate the acceptable satellite elevation angles in day-time. According to IRI-90+DEP models the choice of the single layer height is not so crucial, except for the period around sunrise (or sunset) where the median height proved to be preferable, therefore in mid latitudes the $400 \mathrm{~km}$ seems to be a good choice.

The linear trend of the geometry- and ionosphere-free linear combination, measured by TurboRogue receiver, causes the asymmetry between the code and phase measurements, therefore their special combination is proposed as optimum ionospheric observable. The standard deviation of the fit of the linear trend shows the limitation of absolute TEC determination using TurboRogue receivers. In the case of PCD measurements $5-10 \mathrm{~cm}$ standard deviation, while in the case of XCR measurements $15-20 \mathrm{~cm}$ can be expected.

The measurement errors and the code synchronization biases may cause the wrong sign of the ionospheric delays in the case of low electron density at night. In that case the IRI-90 and the plasmaspheric models are recommended to estimate the preliminary biases especially for XCR observations.

The practical drawback of the recent version of the IRI model is the sharp discontinuity of the ion components during sunset and sunrise at an elevation of $1000 \mathrm{~km}$, because it also causes a sharp discontinuity in the TEC values computed from the attached diffusive equilibrium model of the plasmasphere. The GPS data may be a good source to improve the top side region of the IRI model in future versions.

\section{Acknowledgements}

This study was supported by the European project CEE-CIPA CT93-0130 and the State Scientific Research Fund (OTKA) through grants T4310 and A125.

\section{REFERENCES}

BÁNYAI, L. and I. EPER-PÁPAI (1996): Comparison of cross-correlation and P-code tracking of TurboRogue GPS receiver, Boll. Geod. Sci. Affini, 1, 9-24,

BÁNYAI, L. and M. GIANNIOU (1997): Comparison of TurboRogue and Trimble SSi GPS receivers for ionospheric investigation under anti-spoofing, $Z$. Vererbungsl. (Heft 3), 122, 136-142.

BAUER, S.J. (1973): Physics of Planetary Ionospheres (Springer-Verlag, Berlin).

GEORGIADOU, Y. (1994): Modelling the ionosphere for an active control network of GPS stations, in LRG-Series, publication of the Delft Geodetic Computing Centre, No. 7.

KLOBUCHAR, L.A. and R. LeITINGER (1993): On the potential for improving topside electron density profiles using measurements of total electron content, in PRIME Studies with Emphasis on TEC and Topside Modelling, Wissenschaftlicher Bericht No. 2/1993/Teil 1, Institut für Meterologie und Geophysic, Karl-Francens Universität Graz, 13-20.

Klobuchar, L.A., P.H. Doherty and K. Davies (1994): Limitations in determining absolute total electron content from dual-frequency GPS group delay measurements, in Proceedings International Beacon Satellite Symposium, Aberystwyth, U.K., edited by L. KERSLEY, $1-4$.

LANYI, G.E. and T. RoTH (1988): A comparison of mapped and measured total ionospheric electron content using global positioning system and beacon satellite observations, Radio Sci., 23, 483-492. 
LinCOLN, J.V. and R.O. Conkright (Editors) (1981): Report UAG-82 - International Reference Ionosphere, World Data Center A for Solar-Terrestrial Physics.

Press, W.H., B.P. Flannery, S.A. Teukolsky and W.T. VetTERLING (1986): Numerical Recipes (Cambridge University Press, New York).

WANNINGER, L. (1992): Monitoring total ionospheric electron content and ionospheric irregularities with GPS, in Refraction of Transatmospheric Signal in Geodesy, edited by J.C. DE MunCK, and T.A.TH. SPOELSTRA,
Netherland Geodetic Commission, Publications on Geodesy, New Series, No. 36, 141-146.

WANNINGER, L., E. SARdon and R. WARNANT (1994): Determination of the total electron content with GPS Difficulties and their solution, in Proceedings International Beacon Satellite Symposium, Aberystwyth, U.K., edited by L. KERSLEY, 13-16.

(received November 20, 1996; accepted September 20, 1997) 